\title{
The Mediating Role of Subjective-Wellbeing in Terms of Perceived Stress and Hypertension
}

\begin{abstract}
Background and objective: Hypertension is a psycho-physiological problem. There are several biological and psychological factors that affect the incidence and severity of hypertension. The present study was aimed to investigate the mediating role of subjective-wellbeing in terms of perceived stress and hypertension.

Materials and methods: In this descriptive-correlated study, the study population included over-45-adult patients with hypertension who referred to health centers in Tehran. Through convenience sampling 298 persons (121 male and 177 female) were selected as samples of the study. Perceived stress scale questionnaire and subjective well-being questionnaire were used to gather the data. To analyze the data Structural equation modeling (SEM) was used.

Results: There was a significant and negative correlation between subjective well-being and hypertension ( $<<0.01, \beta=0.353$ ). The subjective well-being mediates the relationship between perceived stress and hypertension $(p<0.01$, $\beta=0.203$ ) and scores of perceived stress and subjective well-being explain the percentage of variance in blood pressure and changes in scores of perceived stress explain $45 \%$ of variance in subjective well-being.

Conclusion: People with high blood pressure have high perceived stress and subjective well-being contributes to the control of hypertension.

Paper Type: Research Article.

Keywords: Perceived stress, Subjective well-being; Hypertension, Tehran.

Citation: HagRanjbar F., Shirzad M., Taghdisi M.H., SaramiFooroshani G.R., Ahadi H. The Mediating Role of Subjective-Wellbeing in Terms of Perceived Stress and Hypertension. Iran J Health Educ Health Promot. Spring 2016;4(1):5057.
\end{abstract}

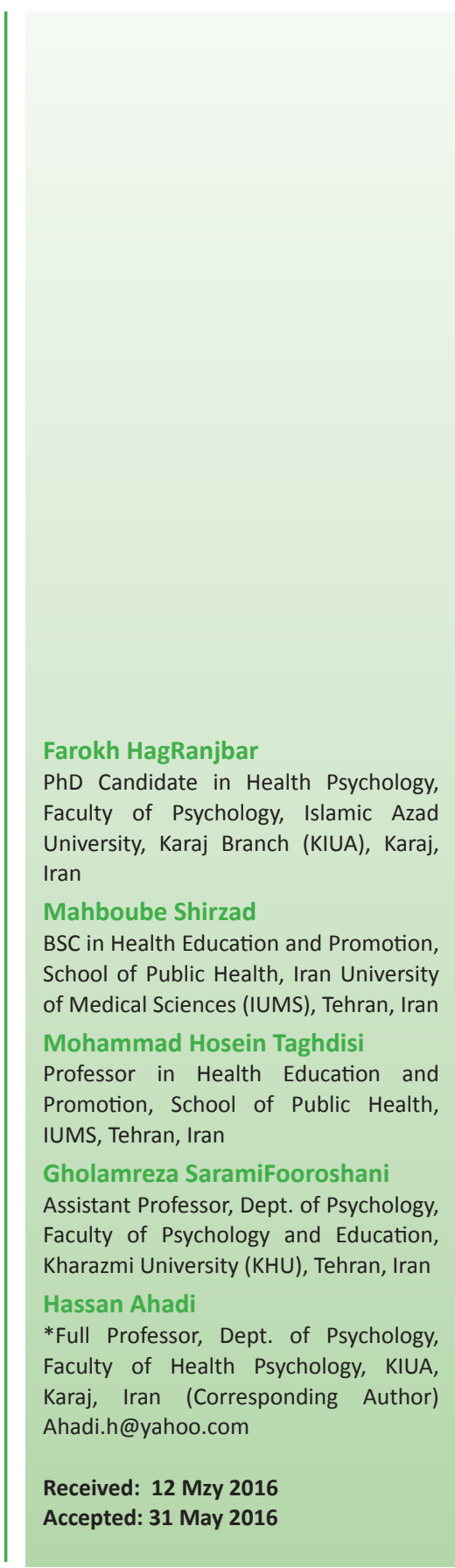


فرخ حقرنجبر

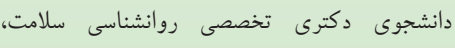

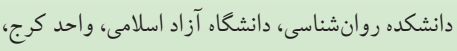
كرج، ايران محبوبه شيرزاد كارشناسى ارشد آموزش بهداشت و ارتقاى سلامت،

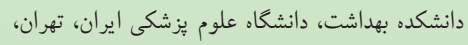

ايران

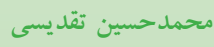
استاد آموزش بهداشت و وارتقاى سلامت، دانشكده بهداشت، دانشحاه علوم يزشكى ايران، تهران، ايران

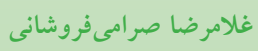

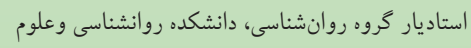
تربيتى، دانشكاء خوارزمى، تهران، ايران.

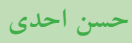

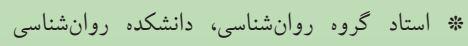
سلامت، دانشكاه آزاد اسلامى، واحد كرج، كرج، دور، ايران

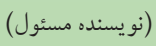

\section{Ahadi.h@yahoo.com}

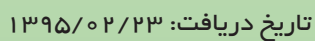

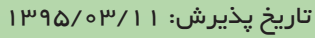

\section{0}

زمينه و هدف :يرفشارى خون يك اختلال روانى فيزيولوزيك است كه علاوه بر عوامل زيستى و خطر ساز

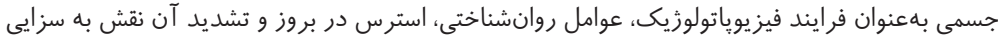

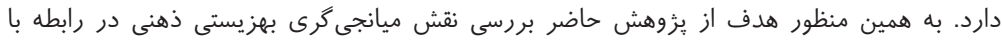

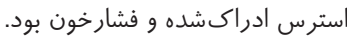

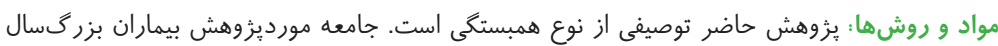

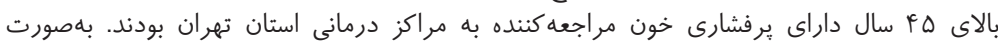

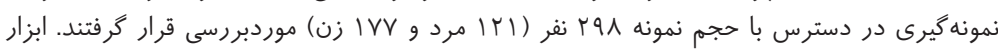

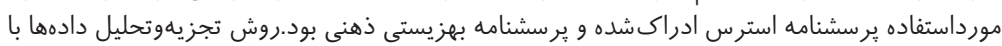

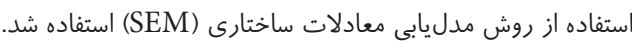

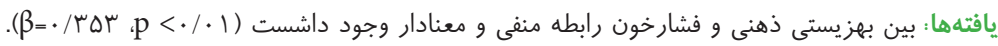

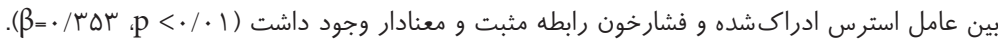

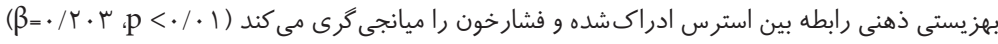

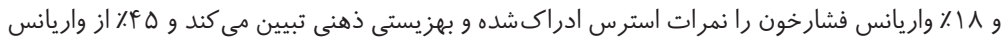

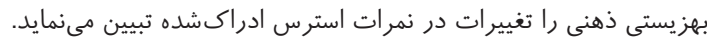

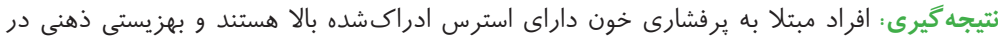
كنترل فشار خون نقش دارد.

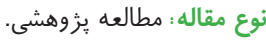
كليدوازه: يرفشارى خون، استرس ادراكش مُوه، بهزيستى ذهنى، تهران.

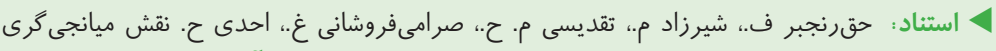

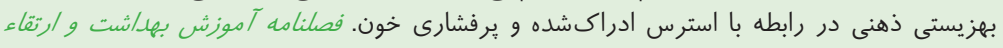

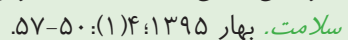




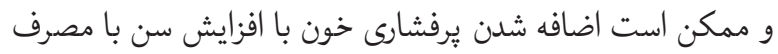

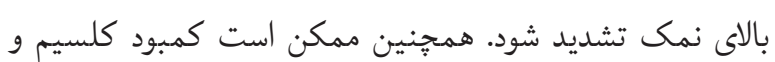
يتاسيم در رثيم غذايى نيز در بروز برفشارى خون نقش داشته باشد.

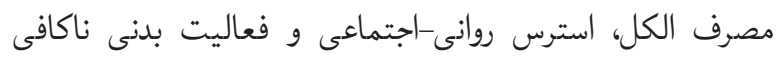

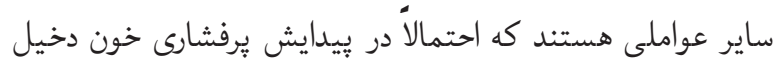

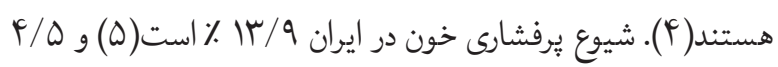

\% از بار بيمارىها را در جهان به خود اختصاص داده است( (9).

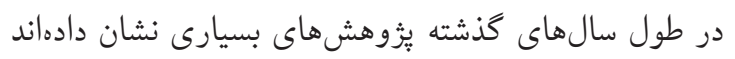

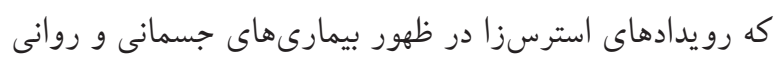

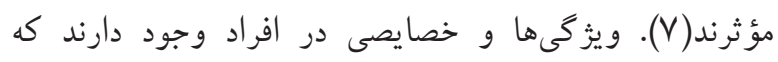
آنها را بهطور بالقوه مستعد دريافت تجربه استرسزا مئى كند.

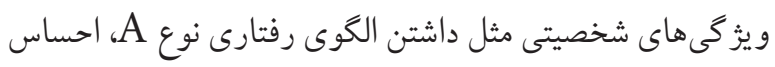

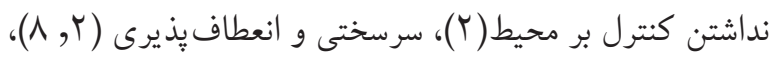

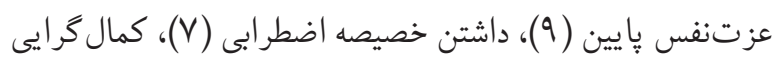

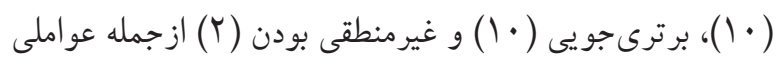

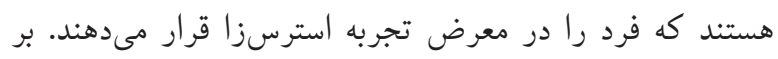

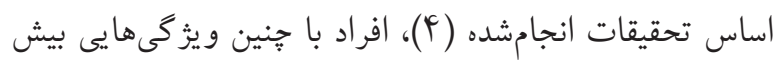
از سايرين درخطر استرس و انواع بيمارىهاى جسمى قرار دارند.

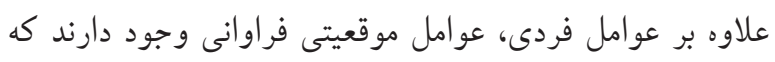

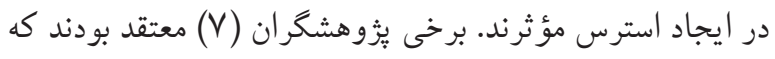

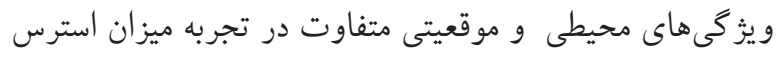
اثر گذار هستند. بر اين اساس، حوادثى كه تقاضاها و مطالبات

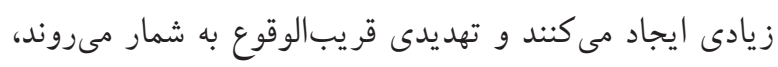

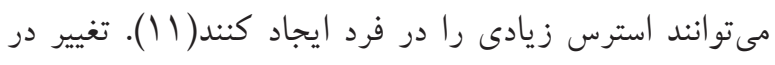
شرايط محيطى و زندكى را نيز استرسآور دانستند. عوامل

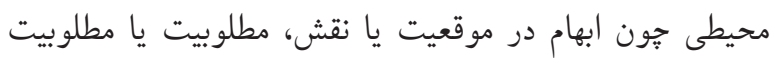

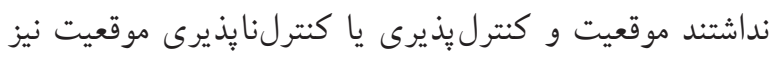

در ميزان تجربه استرس مؤثر هستند (T, Y).

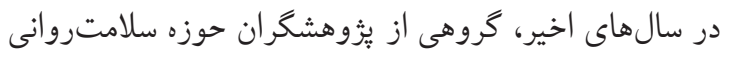

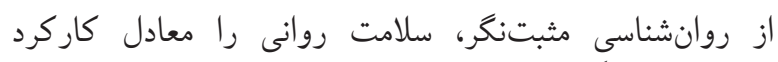

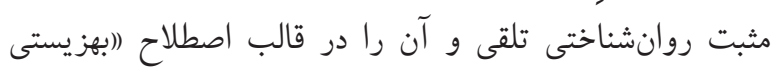

هييرتانسيون' يا يُرفشارى خون، نشانكانى است كه ويثگى آن افزايش فشار سرخرى سيستميك است. ازلحاظ بالينى فردى را

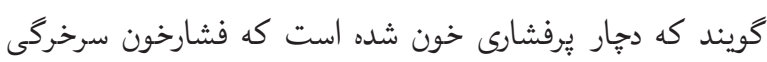

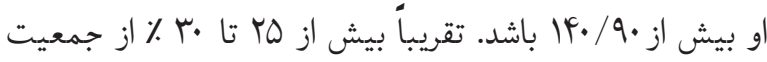

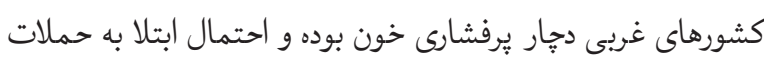



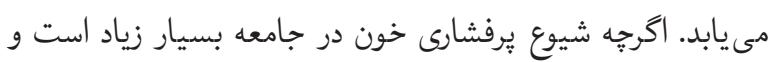

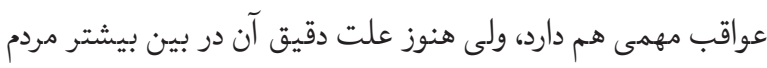

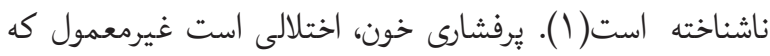

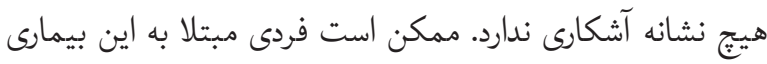

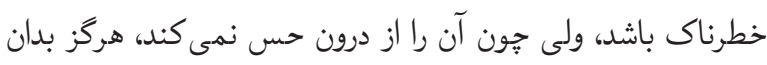

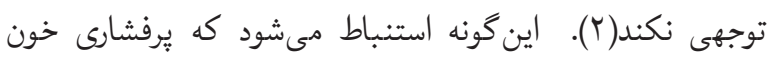
مربوط به زمانى است كه فرد احساس فشار يا تنش مى كندي، ولى استى

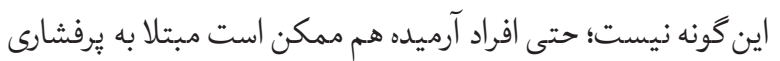

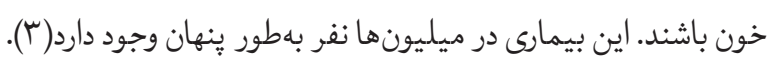

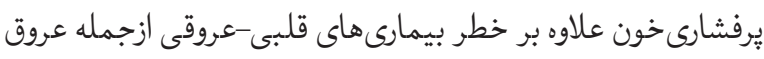

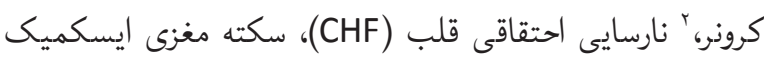

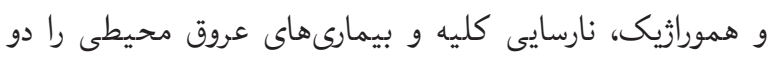

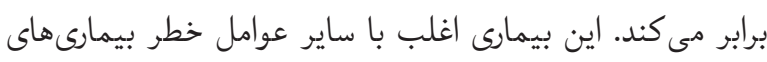

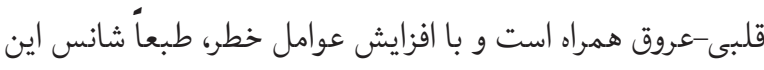

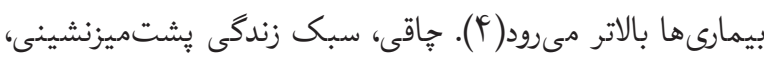

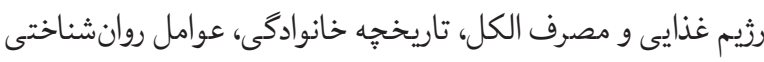

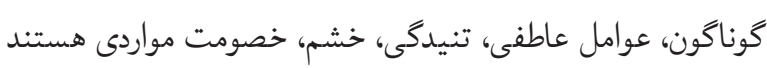

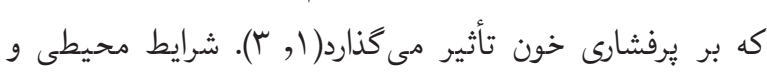

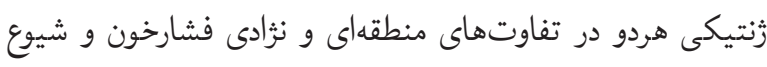

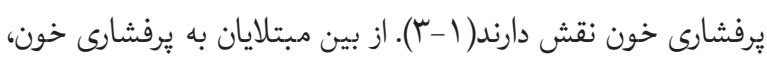

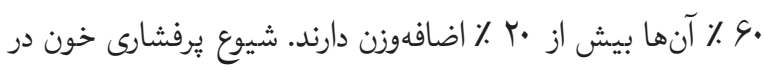
جمعيتهاى مختلف با ميزان نمك طعام در رثيم غذايى ارتباط دارد

1.Hypertension

2. Coronary Heart Disease (CHD) 
روانشناختى) مفهو سازى كردهاند. اين گروه نداشتن بيمارى را را موردمطالعه قرار دهد. براى احساس سلامت كافى نمىدانند؛ بلكه معتقدند كه داشتن

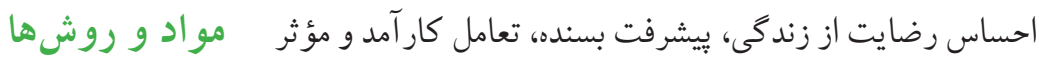
با جهان، انرذى و خلق مثبت، ييوند و رابطه مطلوب با جمع و يزّوهش حاضر از نوع مطالعه توصيفى همبستكى بود. جامعه

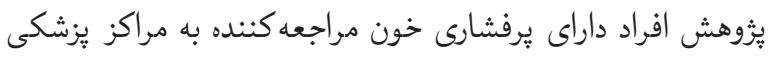

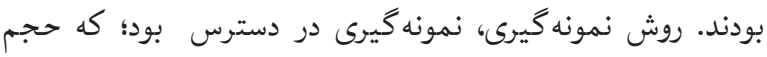

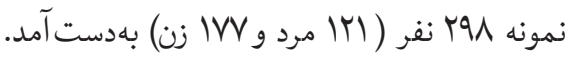
از دو ابزار در اين يُزوهش مورداستفاده قرار كرفت: (1) يرسشنامه استرس ادراكشده و (Y) مقياس بهزيستى ذهنى. دوردي.

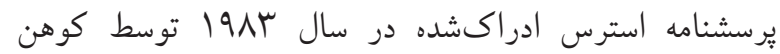

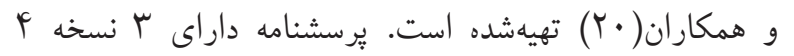

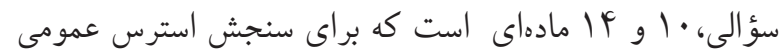
دركشده در يك ماه كذشته به كار مىرود. اين ابزار، افكار و

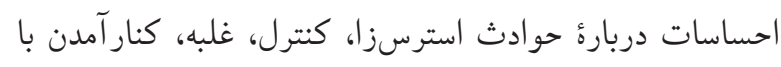
فشار روانى و استرسهاى تجربهشده را موردسنجش قر ار مى دهد.

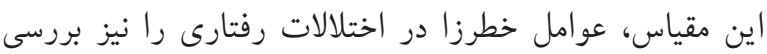

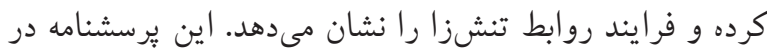

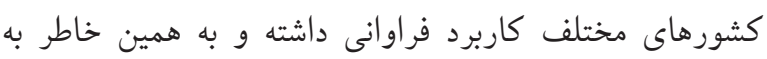
زبانهاى گوناگون ترجمه و در كشورهاى زيادى مورداستفاده

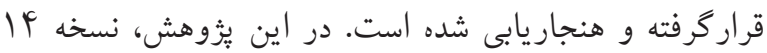
مادهاى آن استفادهده است. آلفاى كرونباخ براى اين مقياس

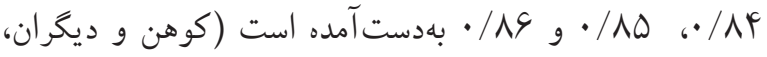

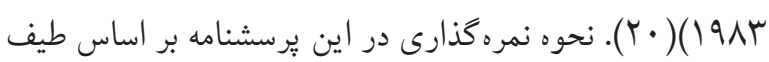

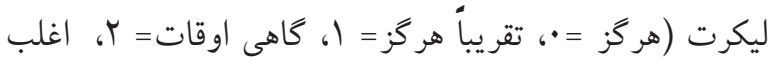

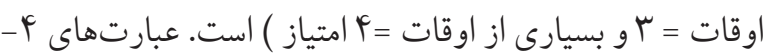

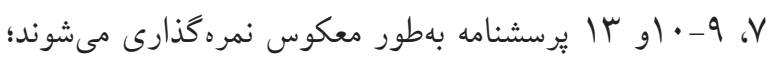
كمترين امتياز كسبشده صفر و بيشترين امتياز وه است. نمره بالاتر نشاندهنده استرس ادر اكشده بيشتر است.

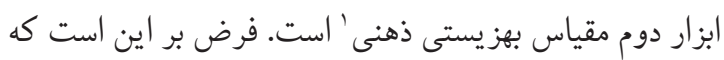
رضايت از زندكى بعد شناختى و عاطفه مثبت و نبود عاطفه منفى نيز بهزيستى روانشناختى را برحسب شكوفايى انسانى و درك

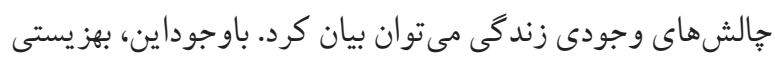
روانشناختى را مىتوان به صورتهاى مختلفى عملياتى نمود. اين

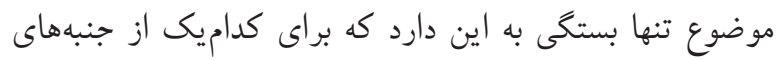

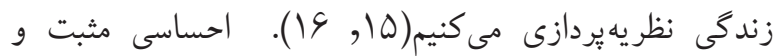
احساس رضامندى عمومى از زندگى، شامل خود و ديكران در

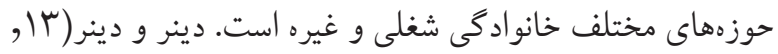
19) بهزيستى روانشناختى را ارزيابى هاى شناختى و عاطفى افراد

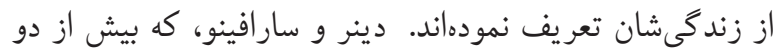

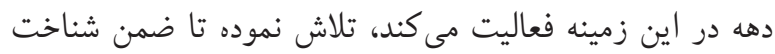

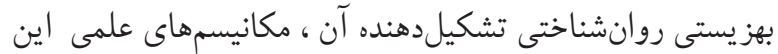

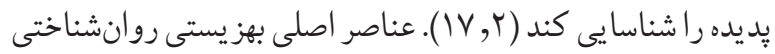

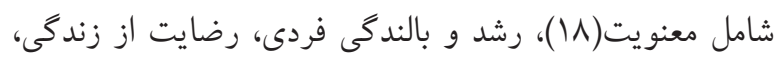

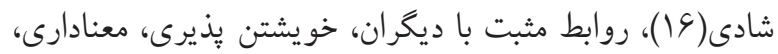
ساز كارى و تسلط بر محيط، خودييروى، خوشبينى(IV) و داشتن هدف در زندگى است. رخدادهاى زندكى بهصورت يكسان افراد را تحت تأثير قرار نمىدهند؛ بلكه شيوه تفسير افراد از رخدادها است

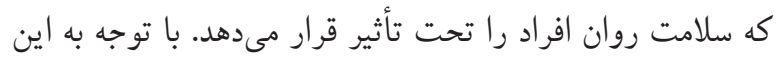
كه يك رخداد منفى ممكن است ازنظر فردى يك فاجعه و ازنظر فردى ديكر يك فرصت تلقى شود(9 (1). استرس بهواسطه شيوههاى تردي مقابلهاى افراد بر بهزيستى ذهنى آنان تأثير مى گذارد(ه (1). نتايج

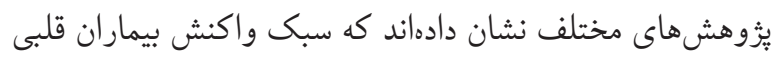

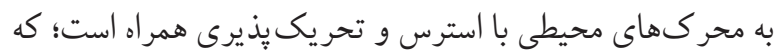
خود موجب عوارض قلبى -عروقى مانند يرفشارى خون در آنان

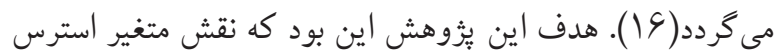

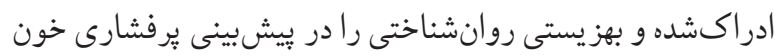


براى تجزيهوتحليل دادها از روش مدليابى معادلات

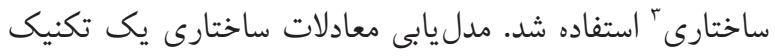
تحليل جندمتغيرى بسيار كلى و نيرومند از خانواده ركرسيون جندمتغيرى است كه به يُوهشكر امكان مىدهد مجموعهاى از

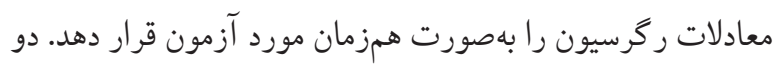

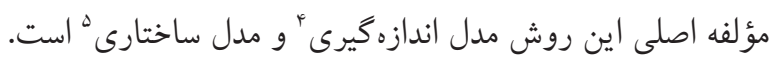
به همين دليل تحليل مدليابى معادلات ساختارى مستلزم كذر از از دو مرحله است: بررسى مدل اندازهيرى از طريق تحليل عاملى

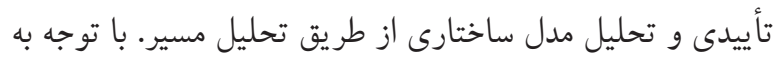

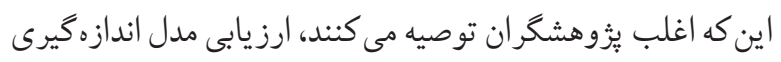

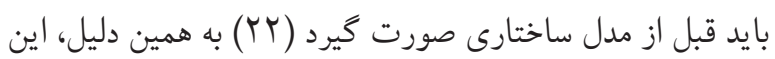
مر احل در اين يُووهش به ترتيب معمول انجام شده است.

يافتهها نتايج اين مطالعه نشان مى دهد كه استرس هم بهصورت مستقيم

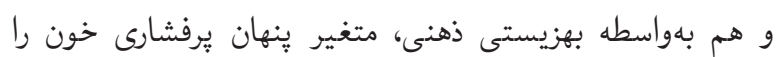

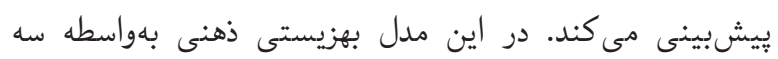

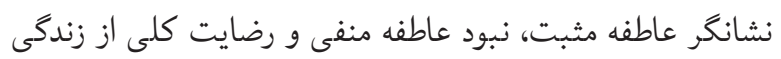
و متغير بنهان برفشارى خون از طريق دو نشانكر فشارخون

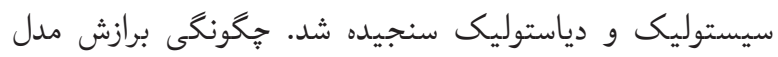

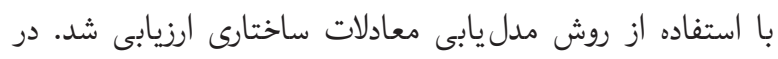

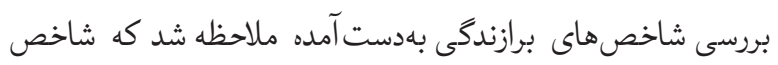

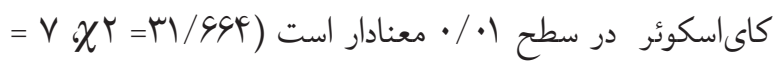
(N= Y9A d df

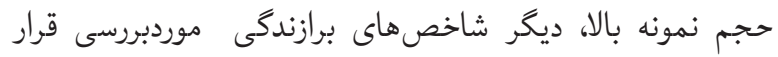

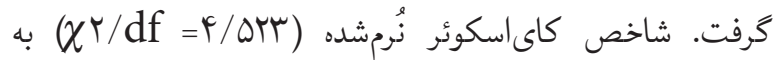
همراه ديكر شاخصهاى برازندكى مثل شاخص برازندگى تطبيقى

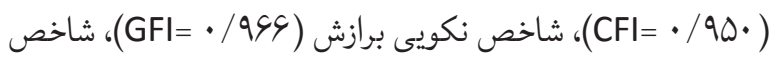

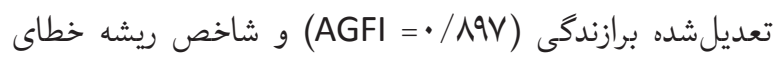

3. Structural Equation Modeling (SEM)

4. Measurement model

5. structural model
بعد هيجانى بهزيستى ذهنى را اندازهيرى مى كنند. ضرورى است

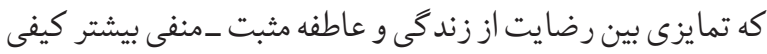
وجود دارد. بهعبارتديكر، درحالى كه رضايت از زندگى به قضاوت

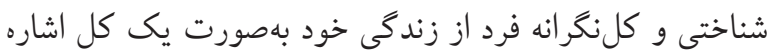

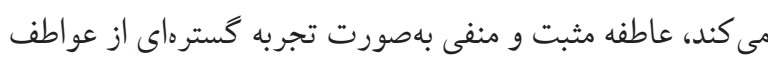
مثبت و منفى تعر يف مى شود. بهز يستى ذهنى به نمر ات بهدست آمداه از مقياسهاى عاطفه مثبت، عاطفه منفى و رضايت كلى از زندكى

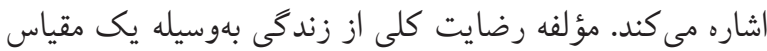

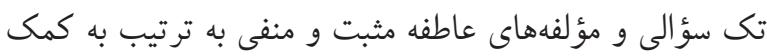

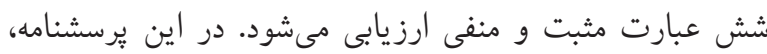

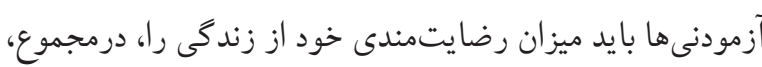
بر روى يك مقياس • إدرجهاى از صفر (بدترين شرايط ممكن) تا •l إبهتر ين شر ايط ممكن) مشخص نمايند.

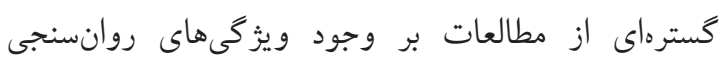

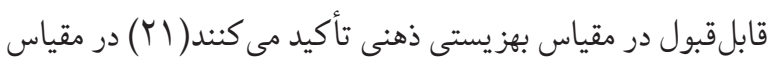

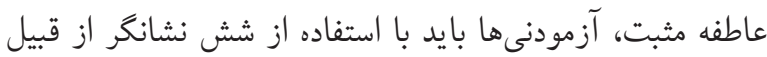

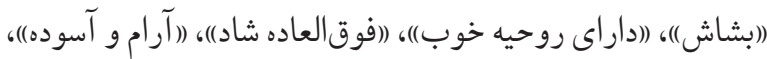
((راضى) و ((سرزنده)' وضعيت خود را بر روى يك مقياس ينج

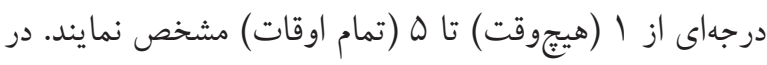

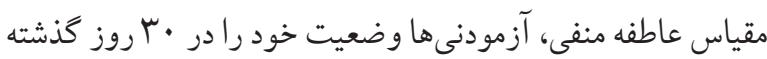

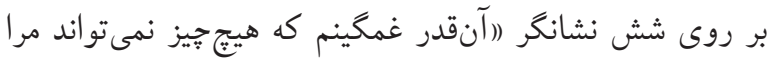



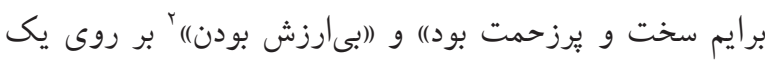

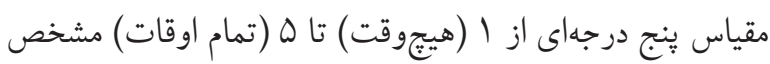

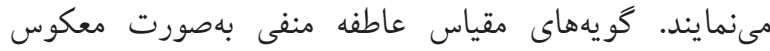
نمرهگذارى مىشوند. بنابراين، نمرات مثبت بالاتر در اين مقياس

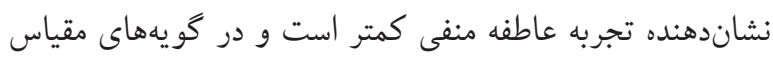
عاطفه مثبت، نمرات بالاتر نشاندهنده تجربه عاطفه مثبت بيشتر

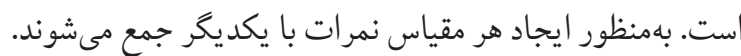

1. Cheerful, In good spirits, Extremely happy, Calm and peaceful, Satisfied, Full of life

2. nervous, Restless or fidgety, Hopeless, Worthless 


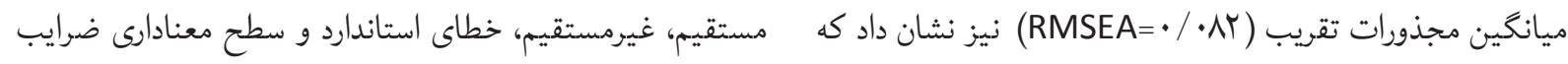
مدل با دادها برازش مطلوبى دارد. جدول ا ضرايب مسير كل، مسير در مدل ساختارى را نشان مىدهد. جدول ا. ضرايب مسير كل، مستقيم و غيرمستقيم يين استرس ادراكشده، بهزيستى ذهنى و فشارخون

\begin{tabular}{|c|c|c|c|c|c|c|}
\hline \multicolumn{2}{|c|}{ اثر غيرمستقيم } & \multicolumn{2}{|c|}{ اثر مستقيم } & \multicolumn{2}{|c|}{ اثر كل } & \multirow[b]{2}{*}{ مسير ها } \\
\hline خطاى استاندارد & استاندارد & خطاى استدارد & استاندارد & 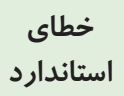 & استاندارد م امتر & \\
\hline.$/ .94$ & $\cdot / r \cdot$ 釆米 &.$/ 11 f$ &.$/ 101$ & $\cdot / \cdot \wedge \Delta$ & 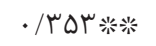 & استرس -فشارخون \\
\hline \multirow[t]{2}{*}{-} & - & - & - &.$/ . \Delta F$ & $-\cdot|9 V|$ 米米 & استرس - بهزيستى ذهنى \\
\hline & & & & .1 .99 & $-\cdot / r \cdot r$ 米米 & بهزيستى ذهنى - فشارخون \\
\hline
\end{tabular}

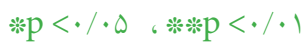

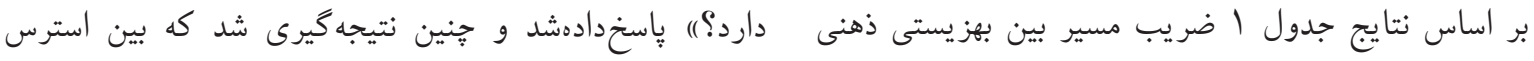

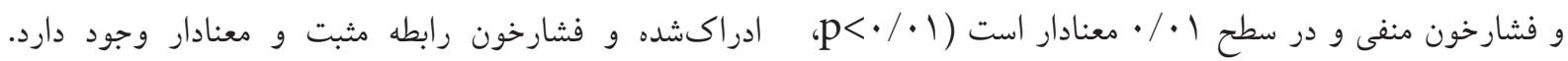

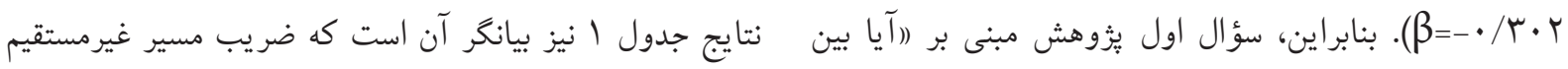

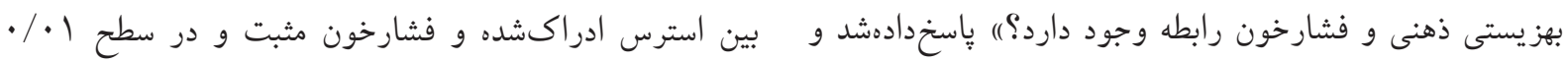

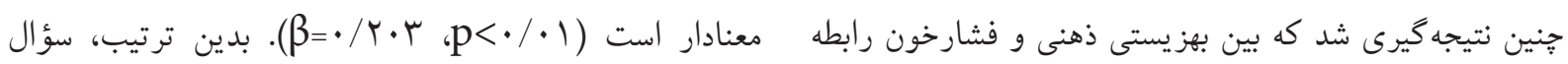

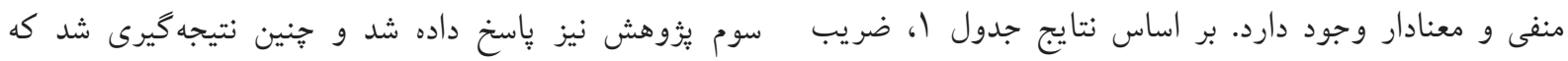

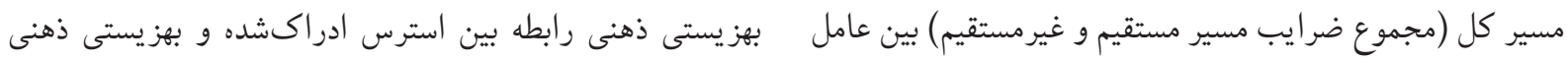

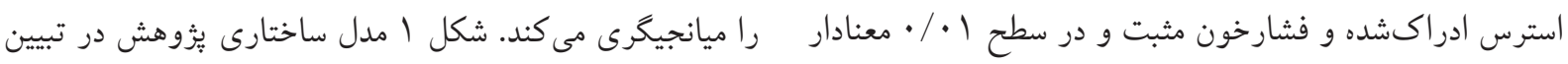

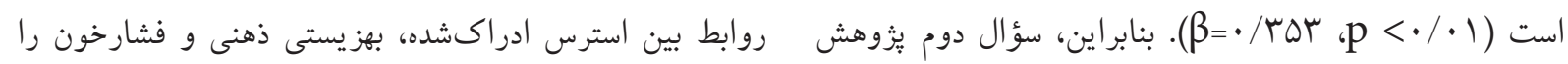

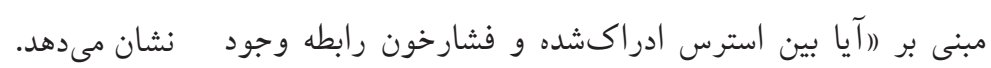



شكل ا. مدل ساختارى يثوهش در تبيين روابط بين استرس ادراكشده، بهزيستى ذهنى و فشارخون 
است كه شاد بودن يكى از مهمترين هدفهاى نوع بشر است. از

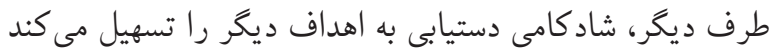
و رفتارهاى مطلوب و ويامدهاى رفتارى مطلوب به دنبال دارد (1)

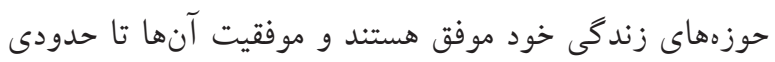

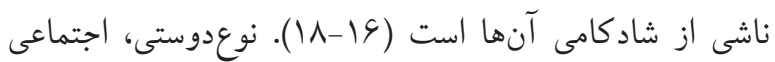
بودن، فعال بودن، دوست داشتن خود و ديخران، داشتن بدنى سالم و قوى و داشتن مهارتهاى بالاى حل مسئله از ويز كىهاى افراد

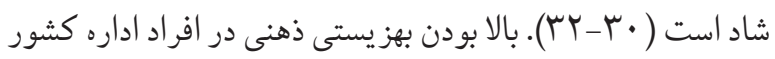

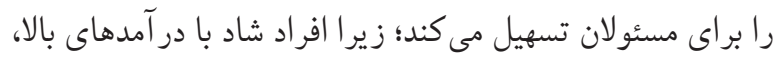

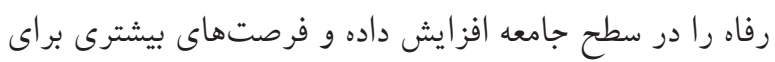

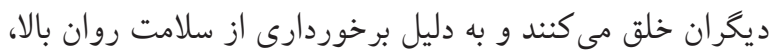

روابط اجتماعى بهترى در سطح جامعه ايجاد مى كنند(T, سب). نتيجه كيرى نوانط اجنمى با توجه به نتايج اين يُوهش بايد عوامل روانى را در فشارخون

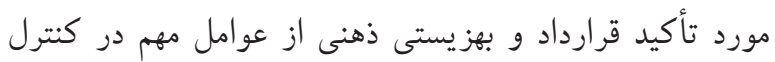

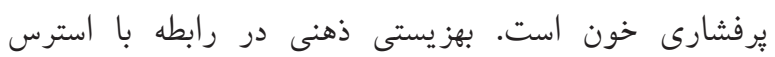
ادراكشده و فشارخون ميانجى كرى مي كند.

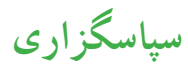
با سياس از كليه افرادى كه در اين يُّوهش همكارى داشتند.

\section{References}

1. Mazloomy Mahmoodabad SS, Tehrani H, Gholian-aval M, Gholami H, Nematy M. The effect of social class on the amount of salt intake in patients with hypertension. Blood pressure. 2016:1-4.

2. Sarafino EP, Smith TW. Health psychology: Biopsychosocial interactions: John Wiley \& Sons; 2014.

3. Taylor SE, Sirois FM. Health psychology: McGraw-Hill New York; 1995.

4. Longo D, Fauci A, Kasper D, Hauser S. Harrison's Principles of Internal Medicine 18th edition: McGraw-Hill Professional; 2011.

5. Mazloomy Mahmoodabad SS, Tehrani H, Gholian-aval M, Gholami H, Nematy M. The effect of social class on the amount of salt intake in patients with hypertension. Blood pressure. 2016:1-4.

6. Tee SR, Teoh XY, Aiman W, Aiful A, Har CSY, Tan ZF, et al. The prevalence of hypertension and its associated risk factors
همجٍنان كه در شكل ا ديده مىشود، مجذور همبستكى هاى

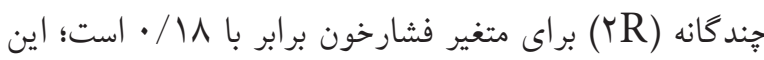

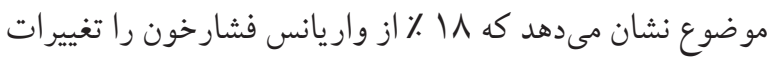
در نمر ات بهز يستى ذهنى و استرس تبيين مى كند. همجِنين مجذور



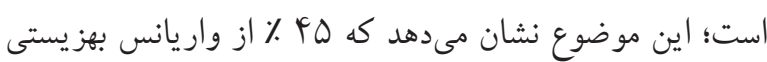
ذهنى را تغييرات در نمر ات استرس ادراكشده تبيين مى كند.

نتايج نشان مىدهد كه بين بهزيستى ذهنى و فشارخون رابطه

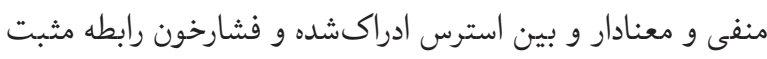

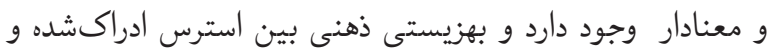

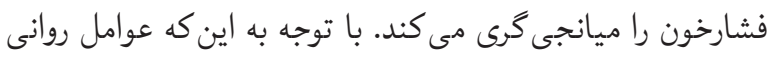

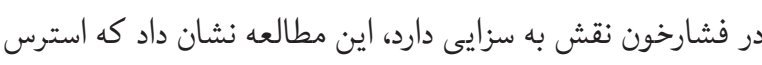

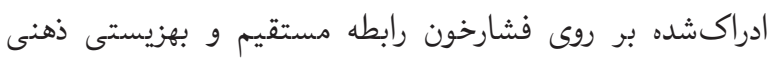

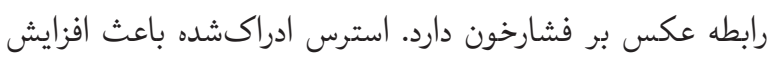
فشارخون مى گردد. اين در حالى است كه بهزيستى ذهنى مى تونواند نقش بهسزايى در جلوكيرى از افزايش فشارخون ايجاد كند. در تبيين يافتهاى يُزوهش مى توان به اين نكته اشاره نمود:

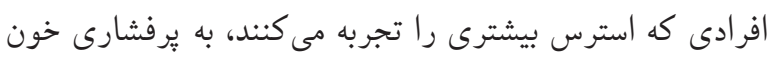

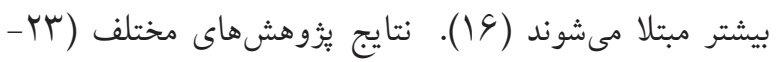

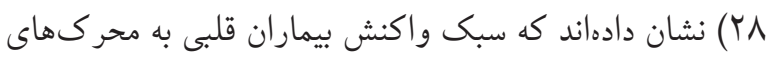

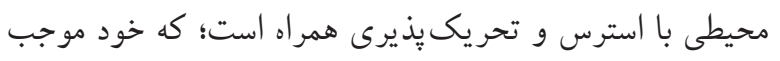

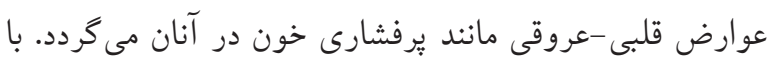

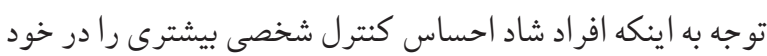

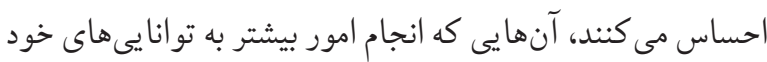

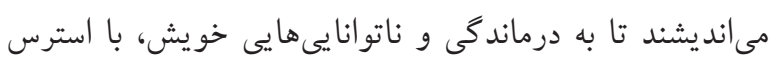
بيشترى مقابله مى كنند؛ به همين دليل نيز كمتر مبتلا به فشارخون

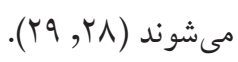

بهزيستى ذهنى مى تواند در سلامت جسمى و روانى افر اد تأثير

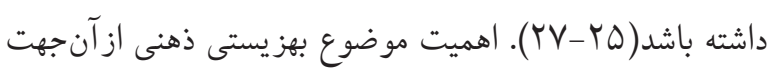


in two rural communities in Penang, Malaysia. IeJSME. 2010;2:27-40.

7. Bardeen JR, Fergus TA. An examination of the incremental contribution of emotion regulation difficulties to health anxiety beyond specific emotion regulation strategies. Journal of anxiety disorders. 2014;28(4):394-401.

8. Badour CL, Feldner MT. Trauma-related reactivity and regulation of emotion: Associations with posttraumatic stress symptoms. Journal of behavior therapy and experimental psychiatry. 2013;44(1):69-76.

9. Compare A, Zarbo C, Shonin E, Van Gordon W, Marconi C. Emotional regulation and depression: a potential mediator between heart and mind. Cardiovascular psychiatry and neurology. 2014;2014.

10. Burns RA, Machin MA. Identifying gender differences in the independent effects of personality and psychological well-being on two broad affect components of subjective well-being. Personality and Individual Differences. 2010;48(1):22-7.

11. Burke RJ, Dahlan A. Malek M, Mearns K, Flin R. Stress and psychological well-being in UK and Malaysian fire fighters. Cross Cultural Management: An International Journal. 2010;17(1):50-61.

12. Diener E. Subjective well-being: The science of happiness and a proposal for a national index: American Psychological Association; 2000.

13. Diener E, Diener M. Cross-cultural correlates of life satisfaction and self-esteem. Culture and well-being: Springer; 2009. p. 71-91.

14. Diener E, Oishi S, Lucas RE. Personality, culture, and subjective well-being: Emotional and cognitive evaluations of life. Annual review of psychology. 2003;54(1):403-25.

15. Tehrani H, Rakhshani T, Zadeh DS, Hosseini SM. Analyzing the relationship between job stress to mental health, personality type and stressful life events of the nurses occupied in tehran 115 emergency. Iranian Red Crescent Medical Journal. 2013;15(3):272-3.

16. Diener E, Lucas RE, Scollon CN. Beyond the hedonic treadmill: revising the adaptation theory of well-being. American Psychologist. 2006;61(4):305.

17. Diener E, Scollon CN, Lucas RE. The evolving concept of subjective well-being: The multifaceted nature of happiness. Advances in cell aging and gerontology. 2003;15:187-219.

18. Diener E, Seligman ME. Beyond money toward an economy of well-being. Psychological science in the public interest. 2004;5(1):1-31.

19. D’Aniello GE, Scarpina F, Mauro A, Mori I, Castelnuovo G, Bigoni $\mathrm{M}$, et al. Characteristics of anxiety and psychological well-being in chronic post-stroke patients. Journal of the neurological sciences. 2014;338(1):191-6.

20. cohen.s KT, Mermelstin,R. A global maasure of perceived stress journal of Health and Social Behavior. 1983(24):385-96.

21. Keyes CL, Shmotkin D, Ryff CD. Optimizing well-being: the empirical encounter of two traditions. Journal of personality and social psychology. 2002;82(6):1007.

22. Ho R. Handbook of univariate and multivariate data analysis and interpretation with SPSS: CRC Press; 2006.

23. Monteiro NM, Balogun SK, Oratile KN. Managing stress: the influence of gender, age and emotion regulation on coping among university students in Botswana. International journal of adolescence and youth. 2014;19(2):153-73.

24. Montes-Berges B, Augusto-Landa J-M. Emotional intelligence and affective intensity as life satisfaction and psychological well-being predictors on nursing professionals. Journal of Professional Nursing. 2014;30(1):80-8.

25. Quevedo RM, Abella MC. Does locus of control influence subjective and psychological well-being? Personality and Individual Differences. 2014;60:S55.

26. Ratchford EV, Carson KA, Jones SR, Ashen MD. Usefulness of coronary and carotid imaging rather than traditional atherosclerotic risk factors to identify firefighters at increased risk for cardiovascular disease. The American journal of cardiology. 2014;113(9):1499-504.

27. Scheibe $S$, Zacher $H$. A lifespan perspective on emotion regulation, stress, and well-being in the workplace. Research in occupational stress and well-being. 2013;11:167-97.

28. Zheng $G$, Lan $X$, Li M, Ling $K$, Lin $H$, Chen $L$, et al. The effectiveness of Tai Chi on the physical and psychological well-being of college students: a study protocol for a randomized controlled trial. Trials. 2014;15(1):129.

29. Wood AM, Joseph S. The absence of positive psychological (eudemonic) well-being as a risk factor for depression: A ten year cohort study. Journal of affective disorders. 2010;122(3):213-7.

30. Ecclestone K. From emotional and psychological well-being to character education: challenging policy discourses of behavioural science and 'vulnerability'. Research Papers in Education. 2012;27(4):463-80.

31. Feicht T, Wittmann M, Jose G, Mock A, von Hirschhausen $E$, Esch T. Evaluation of a seven-week web-based happiness training to improve psychological well-being, reduce stress, and enhance mindfulness and flourishing: A randomized controlled occupational health study. Evidence-Based Complementary and Alternative Medicine. 2013;2013.

32. Hinkley T, Teychenne M, Downing KL, Ball K, Salmon J, Hesketh KD. Early childhood physical activity, sedentary behaviors and psychosocial well-being: a systematic review. Preventive medicine. 2014;62:182-92.

33. Kato K, Pedersen NL. Personality and coping: A study of twins reared apart and twins reared together. Behavior genetics. 2005;35(2):147-58. 